\title{
The lived experience by psychiatric nurses of aggression and violence from patients in a Gauteng psychiatric institution
}

\author{
E Bimenyimana (MCur): Doctoral Candidate \\ Department of Nursing Science, University of Johannesburg
}

M Poggenpoel (PhD, RN): Professor

Department of Nursing Science, University of Johannesburg

C Myburgh (DEd, MCom, BSc (Hons), HED): Professor

Department of Educational Psychology, University of Johannesburg

$\checkmark$ van Niekerk (MCur): Lecturer

Dept of Nursing, University of Johannesburg

\section{Kevwords:}

Lived experience, aggression, nurses, patients, aggression and violence and psychiatric institution.

\section{Correspondence address}

Prof Marie Poggenpoel.

Department of Nursing Science, University of Johannesburg,

Box 524,

Auckland Park, 2006

Tel no: 011-559-2860

Fax: 011-559-2257

E-mail:mariep@uj.ac.za

\begin{abstract}
Curationis 32 (3): 4-13
Caring for good people is difficult enough; to care for people who are either aggressive or violent is even more difficult. This is what psychiatric nurses working in the psychiatric institution in which research was done are exposed to on a daily basis. The aim of the research was to explore and describe the lived experience by psychiatric nurses of aggression and violence from patients in a Gauteng psychiatric institution. A qualitative, explorative, descriptive, and contextual study design was utilised. Data was collected by means of semi-structured interviews and naive sketches. Tesch's (Creswell, 2004: 256) method of open coding and an independent coder were utilised for data analysis.

This study shed some light on the lived experience by psychiatric nurses of aggression and violence from patients in a Gauteng psychiatric institution. The findings show that the level of violence and aggression to which psychiatric nurses are exposed is overwhelming and the consequences are alarming. The contributing factors to this violence and aggression are: the mental status and the conditions in which patients are admitted; the staff shortage; the lack of support among the members of the multidisciplinary team (MDT); and the lack of structured and comprehensive orientation among newly appointed staff members.

As a result, psychiatric nurses are emotionally, psychologically, and physically affected. They then respond with the following emotions and behaviour: fear, anger, frustration, despair, hopelessness and helplessness, substance abuse, absenteeism, retaliation and the development of an "I don't care" attitude.
\end{abstract}




\section{Background and rationale}

Violence is everywhere and known to almost everyone, yet its impact on society and its consequences to individuals need further studies. In the context of South Africa, aggression and violence have become part and parcel of everyday living. Thus, defining the concepts of aggression, violence, and crime distinctively becomes difficult. It is almost impossible to open a newspaper or watch news on television without reading or seeing scenes of violence and aggression. This state of affairs spares no one, as even babies on their mothers' backs are affected (Seale, Eliseev, \& Rondganger in "The Star", Il October, 2006).

Psychiatric institutions worldwide are known to be encountering a certain level of violence and aggression. Research conducted in countries such as England (Whittington, 2002:819-825), the United States of America (Noble, 2003:389-393), and Australia (Forster, Petty, Schleiger, \& Walters, 2005:357361) among others, bear witness. In South Africa, the research in the hospital environment conducted by Steinman (2003), Kennedy (2004), and Lucas and Stevenson (2006:195-203) shows that violence is present and active in health workplace settings.

In her research on workplace violence in the health sector, Steinman (2003:27) shows that $61.9 \%$ of all the health care workers interviewed had experienced violence of one type or another during the period of 12 months prior to the research study. Further on, she reveals that there are considerable differences in the violence experienced in public health services to that observed in private health services. Steinman (2003. 29) states that the combined percentages for health care workers who had been exposed as either direct or as witnesses of victims to physical workplace violence in both health care sectors were $30.9 \%$. Within the public sector this figure was $42.5 \%$ and in the private sector $19.2 \%$. She then concludes with the following statement: "These are alarming figures and more alarming, the huge discrepancy between the two sectors" (Steinman, 2033: 29).

Despite all these findings, little has been done in South African psychiat- ric institutions with regard to finding out what the psychiatric nurses' lived experiences of aggression and violence from patients are, and the impact of these experiences on the psychiatric nurses' personal life and the service they render to the mental health care users (Bimenyimana, 2008: 3).

\section{Problem statement}

The Mental Health Care Act 17 of 2002 (Government Gazette no. 24024) classifies mental health care users (formerly known as patients) in different categories. Among these categories, the research study focused on Sections 33, 34, and 42. These are: involuntary admitted mental health care users, assisted involuntary admitted mental health care users; and state patients committed pending the court's decision respectively. These mental health care users are admitted on the basis of their being a danger to themselves, a danger to others, and/or a danger to the property of others. In other words, they are admitted because of their violent or aggressive behaviour. Anv attempt $b y$ the psychiatric nurses to give the patient medication may be viewed as an act of aggression. The patients will respond aggressively in what patients believe to be self-defence. The researcher wondered what happened during these or similar incidents to the psychiatric nurses regularly in their working environment in a psychiatric institution (Bimenvimana, 2008:3\&4).

In view of the above background, rationale and problem statement the following questions were posed:

What are the lived experiences by psychiatric nurses of aggression and violence from patients in a Gauteng psychiatric institution where they care for these violent and aggressive users on a daily basis?

What can be done to assist the psychiatric nurses in order to prevent, or to deal effectively with violence and aggression from patients?

\section{Research objectives}

The research objectives were:

- $\quad$ to explore and describe the lived experiences by psychiatric nurses of aggression and violence from patients in a Gauteng psychiatric institution; and

- $\quad$ to describe guidelines to assist the psychiatric nurses to manage the aggression and violence from patients in the psychiatric institution.

\section{Definition of concepts}

Violence: This is the unlawful use of force (Thompson, 1996:16). In this article, violence means any act, word, even attitudes, such as an intimidating facial expression, that creates fear or negative feelings, leading to or resulting in physical or psycho-social unwanted results. This understanding is also extended to any actions, or inaction, premeditated and done consciously or unconsciously, with the intention to harm, whether physically, emotionally, psychologically, or spiritually (Bimenvimana, 2008:7)

Aggression: This is hostile or destructive behaviour (Thompson, 1996: 16). In this article aggression means any behaviour, gesture, verbal or non-verbal communication, with the intention to provoke a negative feeling or negative reaction in another person. This includes intimidation, threats, swearing, undermining, humiliating, indecent exposure and so forth (Bimenyimana, 2008: $7 \& 8$ )

Psychiatric Patient/Mental Health Care User: Government Gazette no. 24024, November 2002 refers to a person with mental illness as a person that is necessary to be detained, supervised, controlled and treated. It includes a person who is suspected of being alleged to be mentally ill to such a degree (Allwood, Gagiano, Gmeiner \& Van Wvk (2002: 268-270). In this article, a Mental Health Care User (psychiatric patient) will mean any person (male or female), aged between 20 and 70 years, admitted because of a mental illness and who has spend at least six uninterrupted weeks in the mental healthcare institution (Bimenyimana, 2008:8)

Psychiatric Hospital/Mental Health Care Institution: This refers to a psychiatric hospital, recognised by the National Health Authority as such and known to care, treat, and rehabilitate people with mental disorders comprehensively (Government Gazette, 2002:10). The institution that will be referred to in this article is a psychiatric hospital (Bimenvimana, 2008:8). 
Psychiatric Nurse: In this article psychiatric nurse refers to a registered psychiatric nurse. The psychiatric nurse is registered at the South African Nursing Council.

\section{Research design}

A research design is defined as a set of guidelines and instructions to be followed in addressing the research problem (Mouton, 1996:107). In this research study, a qualitative, descriptive and contextual research design was utilised (Bimenyimana, 2008: 15-17).

\section{Research method}

The research was conducted in two phases: in phase one the lived experience by psychiatric nurses of aggression and violence from patients in a Gauteng Psychiatric Institution is explored and described (Bimenyimana, 2008:18-24). In phase two guidelines are formulated to assist psychiatric nurses to cope with aggression and violence from patients in their workplace (Bimenyimana, 2008:24).

Sample: a purposive sample of psychiatric nurses was utilised and oneon-one interviews were conducted with participants until saturation (LoBiondo-Wood \& Haber, 1994:257) was reached.

\section{Data Collection}

Interviews can reveal the discourses and language, verbal and non-verbal, which people use to construct their lived realities (Lee \& Stanko, 2003:52). The researcher chose one-on-one interviews because they can provide rich, meaningful insights into participants' experiences and the meanings they attach to them, their feelings, attitudes and values. Interviews were audiotaped; then transcribed. All participants were asked one question: "How is violence and aggression for you in this hospital?" Later on, in order to reach saturation (Shank, 2002:30), a chance was given. to those who preferred to tell their lived experiences of aggression and violence in writing, to write a naive sketch

\section{Data Analysis}

The purpose of data analysis is to attempt to understand what a specific experience is like by describing it as it is found in concrete situation, and as it appears to the people who are living it (Leedy, 1997:161). The researcher utilised open coding (Creswell, 2004:256) to analyse the data. Themes and categories were identified. For the researchers not to be overwhelmed by personal interest, and in order to keep objectivity and reduce bias (Burns \& Grove, 2005:224), an independent coder with academic knowledge and competence in the field was used and a consensus was reached between the researcher and the independent coder. The researchers' task was to try to get to the heart of the matter by looking for themes that lay concealed in the unexamined events of everyday life, to find meaningful, shared themes in different people's descriptions of common experiences (Barritt in Leedy, 1997:162).

\section{Trustworthiness}

Trustworthiness (Bimenyimana, 2008:24-27) refers to gaining knowledge and understanding of the true nature, essence, meanings, attributes, and characteristics of a particular phenomenon under study (Leininger, 1985:68). In order to ensure trustworthiness, the researcher paid attention to the following criteria: credibility, transferability, dependability, and confirmability (Marshall \& Rossman, 1999:192-194). Credibility refers to the compatibility between the constructed realities that exist in the minds of the participants, and those that are attributed to them (Babbie \& Mouton 2001:277). The researcher's attention focuses on the following aspects: prolonged engagement with the field; reflexivity journal; triangulation; member checking; and structural coherence (Lincoln \& Guba, 1985:302-305; Babbie \& Mouton, 2001:277-278).

Transferability refers to the instance to which the findings can be applied in other contexts or with other participants (Babbie \& Mouton, 2001:277). In this regard the researcher used purposive sample; dense description of demographics of participants; and a dense description of results supported by direct quotations of participants. Dependability refers to the evidence that, if the study were to be repeated with the same or similar participants in the same or similar context, itsfindings would be similar (Babbie \& Mouton, 2001: 278). The researcher utilised stepwise replication of the research method; code - recoding of data; and dependability audit:

Confirmability refers to the degree to which the findings are the product of the focus of the inquiry and not of biases of the researcher (Babbie \& Mouton, 2001:278). The researcher used a dependability audit of whole research process: -chain of evidencethe researcher remained faithful to the academic and ethical requirements in conducting the research. The fieldnotes, observation and memos, were kept as guarantee that the findings, conclusions and recommendations were supported by the data and that there was an internal agreement between the researcher's interpretation and the actual evidence.

\section{Ethical considerations}

Gorman et al., (2005:43) point out that ethical considerations are very important, given the fact that participants will provide in-depth highly personal information, and that the information elicited could potentially compromise either the participants or the organisation. In this study, the principles of ethical standards of human dignity and human rights, benefit and harm, autonomy and individual responsibility, consent, privacy and confidentiality, equity and justice, as stipulated by the United Nations Educational, Scientific and Cultural Organisation (UNESCO, 2006) were adhered to and applied (Bimenvimana, 2008: 27-29).

\section{The findings \\ Demographic Information}

All the participants were registered psychiatric nurses who had been working in the institution at least for the last two years. Out of ten participants, five were males and five were females all aged between twenty and forty years old. They all participated voluntarily and willingly (Bimenyimana: 2008: 33 34).

The central theme identified in the data is set out below.

Psychiatric nurses working in this Mental Health Institution experience an overwhelming level of violence and aggression from patients. This violence is real, active, and pervasive. It is expressed verbally, physically, and emotionally, and it has contributing factors and negative consequences. The contributing factors mentioned by the par- 
ticipants are, among others, the type of patients admitted here, staff shortage, lack of support from the management and from the members of the multidisciplinary team (MDT), and the lack of structured and comprehensive orientation. Psychiatric nurses faced with violence from patients experience negative feelings of fear, anger, frustration, despair, hopelessness, and helplessness. They then use ineffective coping mechanisms to deal with violence and aggression from patients. Among these ineffective coping mechanisms are: substance abuse, absenteeism, retaliation, a development of an "Idon't care attitude", and apathy towards the work and towards what is happening around them (Bimenyimana, 2008: 36).

In Table I a summary an overview of the themes and categories identified in the data is given (Bimenyimana, 2008: 37-38).

\section{Theme 1: Contributing factor to violance and agression from patients}

In this theme the contributing factors to aggression and violence from patients in this hospital, as identified by participants, are grouped in four categories below: (Bimenyimana, 2008: 4247).

$$
\begin{aligned}
& \text { type of the patients admitted } \\
& \text { and the hospital environment; } \\
& \text { staff shortages; } \\
& \text { - lack of support by management } \\
& \text { and multidisciplinary team } \\
& \text { (MDT); and } \\
& \text { lack of comprehensive orient- } \\
& \text { tion. }
\end{aligned}
$$

\section{The type of patients}

Patients are admitted in this hospital on the basis of their violent behaviour. In many cases, the family requests assistance from the police who use force to bring the patients to the hospital as if they were criminals making them think of the hospital as if it was a jail. Once in the hospital. the patients display their aggression towards nurses who are thought to be the cause of their admission. This participant said: "Another cause of violence is... our patients are involuntarily admitted You will find that this parient is very angry and bitter against his mother who called the police to bring him here due to committing violence at home after smoking dagga. When he gets here, he then shifts that anger toward you for keeping him here".

\section{Staff shortages}

The shortage of staff makes psychiatric nurses overwork. This results in tiredness and job dissatisfaction. Psychiatric nurses then become discouraged and even absent themselves from work as a sign of protest against the situation in which they find themselves. This situation further decreases the already overstretched number of staff causing more stress and anxiety to those on duty. This is what one of the participants said: "There was a time when a patient was kicking windows and then we had to put her in a side room and we were only two in the ward So we couldn't rake her in a side room and she was fighting us, yeah and our clothes were torn". Another participant mentioned: "As you can see today, I am working alone. I am one registered nurse to 35 patients. This shortage is demotivating."

\section{Lack of support by management and the Multidisciplinary Team (MDT)}

The participants expressed their feelings of isolation and dissatisfaction concerning the support they expect from the management and the MDT. This lack of support is experienced in many ways. Despite the shortage, it seems that the rest of the multidisciplinary team expect the psychiatric nurses do the work of other members of the team, but when psychiatric nurses need $a$ hand there is nobody to help. This participant said: "The nurses are expected to do everything, like when the psychologists come here first of all they will depend on you for assistance but at the end of the dav, they will not respect you. $A$ doctor will expect you to do everything: patients' files and different forms, yer when you are alone, nobod. helps". Another one added: "Usually the doctors will come and prescribe somerhing, but they don't help. You are just left alone there, vou don't get help".

As for management, participants complained that in many instances management is not there to help but to empha- sise the mistakes made by the nurses. This participant said that "When the staff is assaulted, management is on the side of the patient". Another echoed the first saying "When they come (meaning management), they talk to you, but it's like sort of highlighting your wrong doing most of the time. It's all about the patient, the patient, which is ok, but what about you as someone who is working and then who is going through a situation?" This is also coupled with the fact that management is perceived as distant and does not give credit to the nurses where this is due. This is what one participant had to say "It gets too frustrating when you work hard and you are not appreciated The management should learn how to say thank you.. I think the management fails to see that we need support just to build us up."

\section{Lack of structure and effective orientation}

The researcher believes that there is more to the orientation of newly employed psychiatric nurses than telling them what they should and should not do. In this institution, the first week of employment is dedicated to the orientation programme that focuses on the "do's" and "don 't' $s$ " with regard to legal matters. As for what to expect in the wards, this is left to the discretion of the nursing staff in the ward, who themselves went through a similar orientation. What seems to be the problem here is that there is no follow-up after this initial orientation, and despite the differences between wards, the same orientation is applied. The lack of proper and structured orientation leads to frustration and renders newly employed psychiatric nurses more vulnerable to this violence and aggression. These are some of their concerns: one said "I was told by the sisters during orientation that there might be violence but vou don't ger full orientation". Another one said: "The time that I was hit nobody helped me. They just said: you don't have to worry, you are nor bleeding, and it is norhing. In time you will see more". Another one added. "The first time I experienced violence in this hospital / was very, very scared It was a female and I didn't expect that a female could be so violent... we were hiding and I was scared, confused.. nobody said anything to me." 


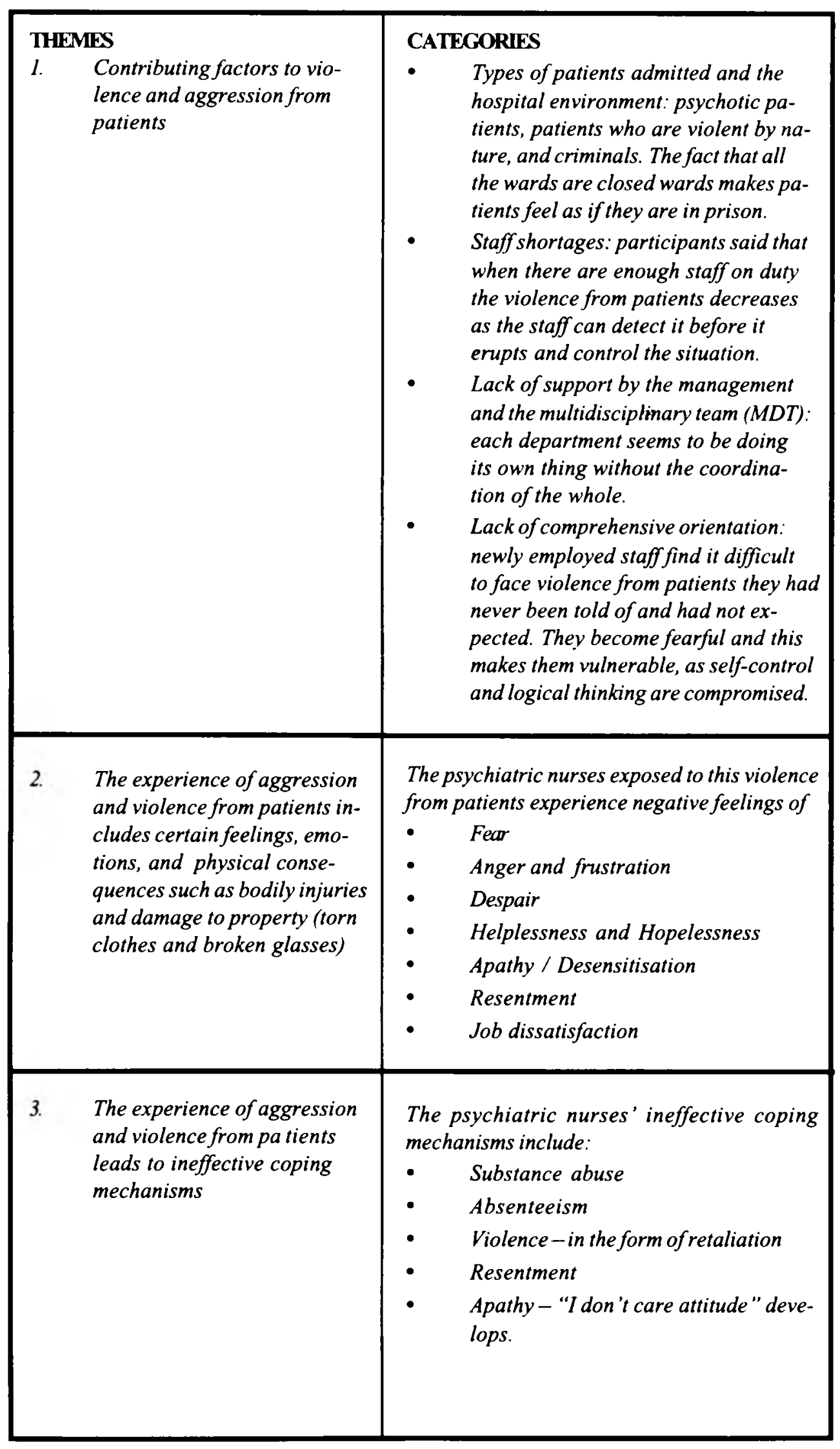

It would be of great value if, once the new nursing staff is employed, to be allocated to a senior nurse for mentoring purposes for at least for six months. This mentor should be chosen based on his or her work ethics and commitment to serve as a role model. The main purpose of this orientation would be not to teach the newly employed psychiatric nurse, but to help $\mathrm{him} / \mathrm{her}$ to adjust to the new working environment (Jooste \& Troskie.
Theme 2: The

experiences of

aggression and

violence from patients include certain feelings and emotions (Bimenyimana, 2008:

\section{7-53)}

\section{Negative Emotions Related to Fear}

Participants verbalised fear in different ways. The main point is that for some participants this fear tends to dictate their reactions and each time they think about going to work, they sense that the day is going to be another risk of being harmed. Hence the work becomes a burden and the working environment is stressful. One said "/ would walk on my way to work, eish, just feeling this heavy load on my shoulders thinking I am going to that place, I'm gonna find so and so and I know they are like this, they are gonna do this". Another one said "If you go to the file and see that they have killed their parents, then they threaten you, you end up hoving fear". This participant added: "There is one patient even who went to the point of saying that we will meet outside. He knows he is gonna get leave and he knows where Istay so we will meet outside and he will get me."

Unmanageable fear makes the caregivers feel small and helpless, unable to think clearly, while a feeling of powerlessness overwhelms them (Carlsson, Dahlberg, Lützen, \& Nystrom, 2004: 191-271).

\section{Anger and Frustration}

Participants talked about experiencing the above emotions basically because they find themselves caught between their vocation for a caring career, and what they perceive as the ingratitude of some of the patients who use their mental condition as a shield and hurt psychiatric nurses, even when the patients are aware of what they are doing. When the nurses become angry, depending on the target, the patients either with- 
draw and harbour resentment or they strike back in retaliation.

Frieze (2005:83) argues that when someone is victimised, another type of response is to become angry and to fight back. This is exactly what one of the participants did as she gives the account: "I was writing the report. He came into the office and said who are you eh... like I was accusing him of something and before I could even look, already he hit me. It was bad and I was so angry. I nearly cried But when I was on my way to the toilet to cry, I decided no. I can give him a clap. I just went in and took him out then I did fight and gave him a bit of his own medicine".

\section{Despair}

The participants 'are of the opinion that they have done all they could and now that the result is not what they expected, they feel like just giving up.

"I can think of nothing good since I came, here except maybe seeing them being well after seeing them coming to the hospital very sick and very psychotic, and then seeing the change. You know it's almost like two different people but then they go home do the same things and come back!"

\section{Helplessness and Hopelessness}

Of all the participants in this research study, not one expressed a hope that things would change for the better. In this battle that the psychiatric nurses are faced with in caring for violent patients, it cannot be sufficiently emphasised how they feel. It would be an understatement to express the feeling of hopelessness and helplessness that one reads on their faces as they talk about their experiences. "The only' thing that helps is giving medication then we hope the patient will be fine because there are patients who came here and we give them medication. They become hetter you send them home, but they go and do the same thing that they' did before."

Needham, Abderhalden, Halfens, Dassen, Haug and Fischer (2005:296300) found that adverse consequences such as avoiding the perpetrator or the perception of an impaired relationship with the patient involved, can lead to psychiatric nurses doubting their professional abilities or even provoke feelings of being a failure.

\section{Apathy / Desensitisation}

Among the many factors that de-motivate psychiatric nurses, the main one is the multiple readmissions of the same mental health care users over and over that make psychiatric nurses feel that they are labouring in vain.

"I am somehow de-motivated because there is no goal; I ask myself what skills am I taking from here?" Another said "Every day you come to work, you are de-motivated. You are just working because you have no choice". One said "I developed an 'Idon't care' attitude because I felt that the management did little or nothing to address the issues."

Lupton and Gillespie (1994:165) discovered that the way many social services staff see their roles leads them to accept a certain level of violence as normal because violence happens all the time. In an earlier study Cherniss (1980:5) had found that professionals who were working in extremely demanding, frustrating, or boring jobs, became less trusting and sympathetic toward clients.

\section{Resentment}

Resentment occurs when dealing with the situation becomes difficult and the end to the problem is not at sight. Some psychiatric nurses resort to keeping everything inside themselves and resenting the person who caused the pain, while waiting for an opportunity to strike back. Most specifically this happens when there is a conflict between a nurse and a member of MDT or management. One nurse said "When we had ward meetings / would be excluded, and my suggestions or opinions would be brushed off. I felt angry and harboured deep resentment 10 wards the sister-in-charge."

Siann (1985:264) argues that it is when people feel at risk both psychologically and physically that the displacement of their emotional insecurity on to others becomes particularly rewarding. Resenting others may, for a while, make the nurse forget the real source of the problem.

\section{Job Dissatisfaction}

The things that de-motivate psychiatric nurses include: the inaction of management; the lack of communication and coordination of activities among the MDT; and the lack of family in- volvement in the treatment and rehabilitation processes of the patients. This makes psychiatric nurses experience that they are doing the same thing over and over admitting the same patients with no end to this vicious circle. Some participants even feel that they have lost direction that they no longer know why they are still working as psychiatric nurses, and they doubt their own caring capacity. This is what one of them had to say: "I am somehow demotivated because there is no goal. Iask myself what skills am Itaking from here?" Another one echoed: "Everyday you come to work, you are demotivated. You are just working because you have no choice".

\section{Theme 3: The experience of agggression and violence from patients leads to ineffective coping mechanisms (Bimenyimana, 2008: 53-}

\section{5)}

\section{Substance Abuse}

Some of the participants mentioned that in order to cope with the amount of aggression and violence from patients, they drink alcohol on a daily basis, whether they are on or off duty. One nurse said: "Maybe that's why in the nurses' home there are so many' bottles empty everiwhere; they drink on an almost daily basis because I know people who drink every day. No matter in or out, off or on duty, every day' they must drink."

Frieze (2005:80) confirms that one of the ways to avoid thinking about a highly stressful event is to get drunk, and he goes on to say that a large majority of people of all ages turn to others to share highly emotional experiences.

\section{Absenteeism}

Although absenteeism first affects the psychiatric nurses who are in regular contact with the patients, some psychiatric nurses absent themselves as a sign of protest and to show dissatisfaction at what is happening. This is hon' some expressed it: "Instead of getting moral suppart from their managers and other members of the team, nursing staff ger blamed for each incident that happens. These things end 
up causing emotional stress to nursing staff and this leads to alcohol abuses and a high rate of absenteeism."

\section{Burnout}

Some psychiatric nurses have come to the point of wondering why they should give their all to the work that is not rewarding. This participant said: "I was not happy with the situation. I thought they did not care, so started wondering why I should care about the hospital and that attitude. Why should I care if people don't care about me"?

Burnout is viewed as the exhaustion of physical or emotional strength as a result of prolonged stress or frustration (Felton, 1998:237-250). The situation in this institution calls for attention because the consequences of burnout are not only detrimental to psychiatric nurses but also to the institution as a whole. Participants mentioned that at times they question why they ended up working in a psychiatric hospital. This study has shown some similarities to Felton's (1998:237-250) findings: the situation reveals an increase in $a b$ senteeism, behavioural changes, expressed by short-temperedness, and chemical abuse shown by daily alcohol drinking.

\section{Job Dissatisfaction}

Job dissatisfaction is often synonymous with burnout and can be associated, and even sometimes identified with, stress. According to Cherniss (1980:158) stress occurs when there is an imbalance between job demands and the workers' resources for meeting them. This participant stated: "It is very challenging and stressful waking up in the morning with the intention of going to help patients, whereas these patients are going to fight you. We end up working for the sake of our families as there is nothing else we can do to survive." Another one added: ".. but the chair landed on my face and injured my nose. I thought of resigning from the institution and seeking employment somewhere else or whether / should let patients fight and not put my life at risk by separating them."

In a situation like this one, when a person starts asking him/herself whether he/she made a right choice, reassurance and sense of being valued are important points. Snyder (2001:290) argues that finding meaning plays a prominent role in the individual's adjustment to negative events. In the aftermath of stressful situations, people want to understand what caused the events to happen, as well as determine the impact of the event on their lives.

\section{Guidelines and recommendations (Bimenyimana, 2008: 59-}

\section{1)}

In formulating guidelines for psychiatric nurses, it would be a mistake to think that a lasting solution can be found without considering the patients, their family environment, and the community as a whole, since the violence is first lived and expressed there. The approach to managing violence and aggression must not only focus on short-term goals but also on longterm goals and the starting point would be to know what violence really is. Gilligan (2000:92) argues that the only way to explain the causes of violence, so that it can be prevented, is to approach it as a problem in public health and preventive medicine, and to think of it as a symptom of life-threatening pathology.

\section{Guideline1: Addressing factors contributing to violence and aggression}

In Table 2 an overview of these guidelines and recommendations is given.

\section{Facilitation of Mental Health}

Approach to Mental Health Care Users There was a general concern among the participants that family members of the mental health care users seem to regard the hospital as a "dumping site". Therefore, intensive health education to the community is needed because most of the family members do not understand what their relatives are going through. and the family members become frustrated and powerless not knowing what to do to help them.

\section{Facilitation of active recruitment of Psychiatric Nurses}

The problem of the shortage of psychiatric nurses is not limited to this hospital; in fact it is a countrywide problem (http://www.sanc.co.za/stats.htm).
However, one cannot fold one's arms and wait for miracles to happen. Empowering the limited number of psychiatric nurses available would be a large part of the solution. To empower the psychiatric nurses, one must take into consideration the environment in which they are working, and their professional and personal development. For example, the report from the exit interviews held by the human resource department of the hospital, shows a pattern of the recurring problem of "inadequate working conditions" as cited by the resigning psychiatric nurses. Improving these conditions may attract more psychiatric nurses, or at least retain those already working there.

Negotiation with management and multidisciplinary team for support

One is left wondering whether it makes sense to the psychiatric nurses that a psychologist can come to the ward for psychotherapy and expect the psychiatric nurses to be the ones to call the patient that he/she is going to be dealing with for the next whole hour or so. Teamwork is also needed as, sometimes, health care workers work against each other instead of working together. What use is it if a doctor prescribes sedation for a violent patient when there are no psychiatric nurses to pin $\mathrm{him} / \mathrm{her}$ down and administer the injection? Management must meet the psychiatric nurses halfway and not wait for a crisis or pretend to ignore a problem when it is there. Murphy et al., (1995:128) argue that too often the threat of exposing anxiety about performance or ill health, or fears of incompetence, or any sign that there is something wrong, forces managers to suppress or deny problems until it is too late.

Request for comprehensive orientation for newly appointed psychiatric nurses Newly employed psychiatric nurses need to know not only what the institution expects from them and how to be legally covered, but also the environment in which they will be operating and what they can expect in the way of challenges and problems related to their work so that they will be able to use a variety of skills (Seybolt in Booyens, 1998:375). The orientation of an employee should be individualised in order to develop those specific skill and abilities required for the present placement (Boovens, 1998:375). Given 


\begin{tabular}{|c|c|}
\hline Themes and Categories & Guidelines \\
\hline $\begin{array}{l}\text { Theme l: Contributing factors to violence and aggression } \\
\text { - } \\
\text { - } \\
\text { - Stape of patients admitted into the hospital } \\
\text { Lack of support by management and multidisciplinary } \\
\text { - } \quad \text { Lam }\end{array}$ & $\begin{array}{l}\text { Guidelinel: Addressing factors contributing to violence and } \\
\text { aggression } \\
\text { - Facilitation of mental health approach to psychiatric } \\
\text { patents } \\
\text { - Facilitation of active recruitment of psychiatric nurses } \\
\text { - Negotiation with management and multidisciplinary } \\
\text { team for support } \\
\text { Request for comprehensive orientation for newly ap- } \\
\text { pointed psychiatric nurses }\end{array}$ \\
\hline $\begin{array}{l}\text { Theme 2: Experiencing aggression and violence arouses the } \\
\text { following feelings and emotions } \\
\text { - } \quad \text { Fear and despair } \\
\text { - } \quad \text { Anger and frustration } \\
\text { - } \quad \text { Helplessness and hopelessness } \\
\text { - Job dissatisfaction }\end{array}$ & $\begin{array}{l}\text { Guideline 2: facilitation of the management of aggression and } \\
\text { violence by psychiatric nurses } \\
\text { - } \quad \text { Management of negative feelings } \\
\text { - Management of aggression } \\
\text { - Coping with stress }\end{array}$ \\
\hline $\begin{array}{l}\text { Theme 3: The Physical consequences of aggression and vio- } \\
\text { lence } \\
\text { - } \\
\text { - } \\
\text { Dodily injuries } \\
\text { glasses to property such as torn clothes and broken }\end{array}$ & $\begin{array}{l}\text { Guideline 3: Addressing the concerns and trying to find solu- } \\
\text { tions to the problem } \\
\text { - Debriefing of psychiatric nurses after incidents of } \\
\text { aggression and violence } \\
\text { Speedy financial compensation }\end{array}$ \\
\hline
\end{tabular}

the fact that the institution has different categories of wards (acute wards, adolescent ward, and forensic wards), it is imperative that orientation be specific and diverse, otherwise, if the necessary supervision of the newly employed nurses is absent, even the best training system will not provide optimum results (Booyens, 1998:27)

\section{Guideline 2: Facilitation of the management of aggression and violence by psychiatric nurses Management of negative feelings}

The negative feelings are a result of a hostile environment and the psychiatric nurses 'inability to cope positively with the situation. One of the ways to manage these negative feelings would be a modification of the environment in which these nurses are working. This can be done by hiring security personnel specifically in the forensic wards where state patients and observation patients are cared for. This also requires a structured environment. One of the participants expressed the following concern: "Two staff members on night duty were attacked by ven dangerous observation patients and were both sent to hospital After some discussions, it was suggested that correctional service personnel or police officers be allocated to that unit. A delegation from correctional services found that the structure of the unit was not suitable for their personnel's safen:"

\section{Management of aggression \\ It appears that the best w'ay of manag- ing aggression in this institution isfind- ing solutions to its leading causes Staff development for example and a change of approach by management may contribute considerably to man- aging aggression. This may boost the morale of the psychiatric nurses, who are already demotivated, and counter the absenteeism that seems to be a major factor contributing to violence.}

\section{Coping with Stress}

Given the situation in which the institution finds itself, it is not possible to eliminate the stress. However, some actions can enable the nurses to live with this stressful environment. Murphy, Hurrell, Sauter and Keita (1995:221) argue that identifying and recognising the problem and taking steps to tackle it, perhaps by negotiation, might arguably mitigate the whole stress process. In dealing with stress, the focus must be on the holistic approach, that is, not only taking into consideration the working environment of the psychiatric nurse, but also his or her home environment. Murphy et al., (1996:228) state that workers do not leave their family and personal problems behind when they go to work, nor do they forget job problems upon returming home. Nearly all models of job stress acknowledge the importance of non-work factors, and their interaction with work factors, in affecting health outcomes.

The strategv to deal with the burnout, or at least to tolerate it, is associated with two occupational factors: length of experience and level of burnout (Whittington, 2002:819-825). 


\section{Guideline 3: Addressing the concerns of nurses and trying} to find solutions to the problem Debriefing of nurses after incidences of aggression and violence

The institution does not have a proper programme to deal with psychiatric nurses' stress-related problems. It relies on the Gauteng employees' wellness programme, called ICAS (Independent Counselling and Advisory Services), that nurses can use for free. However, the participants in this research study said that ICAS is a "faceless" organisation because the initial contact is done on the phone in a conversation with someone one does not know. Again this reflects the lack of teamwork in the institution because the psychological services are there for patients, so why not for the nurses in times of crisis?

\section{Speedy Financial Compensation}

Participants voiced the concern that once their property has been damaged by the mental health care users, or once they have been injured, it takes too much time before they are compensated. The nursing management could negotiate with the human resource department responsible for processing the documentation so that a time frame could be agreed upon, as this would give the nurse victim of this aggression an indication as to how to follow up, and to know how things are progressing.

\section{Limitations}

This research was done in a psychiatric institution with closed wards, and it is unique as there has not been any research on the psychiatric nurses' lived experiences by nurses of violence and aggression from patients in psychiatric institutions in South Africa. Hence this made it difficult as there were not enough theories or literature to analyse and compare the findings with. While the findings are contextualised within this institution, and given the fact that the researcher works in this hospital, an element of bias cannot be totally excluded, though there was no intention on the side of the researcher to be biased. The researcher and participants communicated in English which is not their first language. The richness of expression of what psychiatric nurses feel may have been ham- pered by limits imposed on the expressions of feelings by having to use a foreign language.

\section{Suggestions for further research}

The researcher would like to recommend further studies/researches (Bimenyimana, 2008: 72-73) in this field in order to cover the following issues:

1. the impact of violence and aggression from patients in psychiatric hospital on the professional and personal lives of the psychiatric nurses;

2. the long-term consequences of aggression and violence from patients in psychiatric institutions with regard to the quality of care;

3. the lived experience of aggression and violence from patients in open and semi-open psychiatric hospitals; and

4. the causes and reasons behind the psychiatric patients 'attacks on the psychiatric nurses.

\section{Conclusion}

The purpose of this study was to examine the lived experiences by psychiatric nurses of aggression and violence from patients in a Gauteng psychiatric public institution, the essence of this violence, and how psychiatric nurses experiencing this violence cope with the situation, so that guidelines could be drawn to help those nurses struggling and prepare those contemplating working in a psychiatric institution. Various factors leading to this aggression and violence from patients have been discussed in detail. Guidelines and recommendations have been formulated. It is therefore hoped that more research will follow and that a solution will be developed to end this plight of nurses who are exposed to violence from patients on a daily basis. The hope is that there will be a positive outcome which is the wholistic balanced mental, physical, and psychosocial wellbeing of all those involved in this special calling.

\section{References}

ALLWOOD, C; GAGIANO, C; GMEINER, A \& VAN WYK, S 2002: Handbook of Psychiatric Nursing for Primary Care. New York: Oxford Uni- versity Press.

BABBIE, E \& MOUTON, J 2001: The practice of social research. Southern Africa: Oxford University Press.

BIMENYIMANA, E 2008: The Lived Experience of Aggression and Violence in a Gauteng Psychiatric Institution. Unpublished MCur Psychiatric Nursing Mini-dissertation. Johannesburg. University of Johannesburg

BOOYSENS, SW 1998: Dimensions of Nursing Management. Cape Town. Juta \& Co, Ltd.

BURNS, N \& GROVE, SK 2005: The Practice of Nursing Research: Conduct, Critique, and Utilisation.St Louis, Mis souri: Elsevier.

CARLSSON, G; DAHLBERG, K \& DREW, N 2004: Encountering Violence and Aggression in Mental Health Nursing: A Phenomenological Study of Tacit Caring knowledge. Issues in Mental Health Nursing 21 (5): 533 545.

CHERNISS, C 1980a: Professional Burnout: Job Stress in the Human Services. Praeger: Sage.

CHERNISS, C 1980b: Staff Burnout Job Stress in the Human Service. Praeger: Sage.

CRESWELL, JW 2003: Research Design, Qualitative, Quantitative, and Mixed Methods Approaches. Thousand Oaks: Sage.

DAVIS, DA 1997: Threats Pending Fuses Burning. Managing Workplace Violence. Callfornia: Davies-Black.

FELTON, JS 1998: Burnout as a clinical entity-its importance in health care workers. Occupation Medicine 48 (4). 237-259.

FORSTER, JA; PETTY, MT; SCHLEIGER, C \& WALTERS HC 2005: Violence in Health Care-Policy and Strategy. Know workplace violence: Developing programs for managing the risk of aggression in the health care setting. Medical Journal of Australia 183 (7):357-36I.

FRIEZE, I H 2005: Hurting the One You 
Love: Violence in Relationships. California: Thompson Wadsworth.

GILLIGAN, J 2000: Violence: Reflections on Our Deadliest Epidemic. London: Kingsley.

GOVERNMENT GAZETTE, Republic of South Africa, Mental Health Act 17 of 2002, vol.449 Cape Toun 6 November 2002 No. 24024. Available from internet: http://www.info.gov.za/gazette/acts/2002/a17-02.pdf (accessed 05 March 2007).

GORMAN, GE \& CLAYTON, P 2005: Qualitative Research for the Information Professional. A Practical Handbook. London: Facet Publishing.

JOOSTE, K \& TROSKIE, R 1995: Staff development for nurses. Halfway House, Midrand: Southern Book Publishers.

KENNEDY, M A 2004: Workplace violence: an exploratory study into nurses ' interpretations and responses to violence and abuse in trauma and emergency departments. Masters Dissertation. Western Cape: University of Western Cape.

LEE, RM \& STANKO, E 2003: Researching Violence. London: Routledge.

LEEDY, PD 1997: Practical Research: Planning and Design. Upper Saddle River, New Jersey: Merrill.

LEINIGER, MM 1985: Qualitative Research Methods in Nursing. Orlando: Grune \& Stratton.

LINCOLN, YS \& GUBA, EG 1985: Naturalistic Inquiry. Newbury Park: Sage.

LOBIONDO-WOOD, G \& HABER, J 1994: Nursing Research: methods, critical appraisal, and utilization. St. Louis: Mosby.

LUCAS, M \& STEVENSON, D 2006: Violence and abuse in psychiatric inpatient institutions: $A$ South African perspective. International Journal of Law and Psichiatry. May-June, 29 (3): 195-203.

LUPTON, C \& GILLESPIE, T 1994 :
Working with Violence. London: MacMillan Press.

MARSHALL, C \& ROSSMAN, GB 1999: Designing Qualitative Research. California: Sage.

MOUTON, J 1996: Understanding social Research. Pretoria: Van Schaik Publishers.

MURPHY,LA; HURREL,J;SAUTER, SL \& KEITA, CP 1996: Job Stress Interventions. Washington, DC: American Psychological Association.

NEEDHAMl,I; ABDERHALDEN, C; HALFENS, RJG; DASSEN, T; HAUG, HJ \& FISHER, JE 2005: The Impact of Patient Aggression on Carers Scale: instrument derivation and psychometric testing. Scandinavian Journal of Caring Sciences 19 (3):296-300.

NOBLE, P 2003: Violence in psychiatric in-patients. Review and clinical implications. Psvchiatric Service 54:389393, March. American Psychiatric Association.

SEALE, L; ELISEEY, A \& RONDGANGER, L 2006: Baby shot dead on her mom's back: 15-monthold infant becomes the youngest victim of heist terror. Johannesburg: "The Star". October, 11

SHANK, GD 2002: Qualitative Research. A Personal Skills Approach. New'Jersey: Merrill.

SIANN, G 1985: Accounting for aggression: perspectives on aggression and violence. Boston: Allen \& Unwin.

SNYDER, CR 2001: Coping with Stress: effective people and Processes. Oxford: Oxford University Press.

STEINMAN, S 2003: International Labour Office ILO International Council of Nurses ICN World Health Organization WHO Public Services International PSI Joint Programme on Workplace Violence in the Health Sector Workplace Violence in the Health Sector Country Case Study: South Africa.

THE SOUTH AFRICAN NURSING COUNCIL 2005: Nurses Rights. Available from http://ww' sanc.co.za/ policwights.htm. (accessed 05 March
2007).

THE SOUTH AFRICAN NURSING COUNCIL 2007: Distribution of the population of South Africa versus Nursing Manpower. Available from http:// ww'w.sanc.co.za/stats.htm. (accessed 24 June 2008).

THOMPSON, D (Editor) 1996: The Pocket Oxford Dictionary of Current English. Oxford: Oxford University Press.

UNITED NATIONSEDUCATIONAL, SCIENTIFIC AND CULTURAL ORGANISATION 2006: Division of Science and Technology Social and Human Science Sector. Universal Declaration on Bioethics and Human Rights. Switzerland: UNESCO.

WHITTINGTON, R 2002: Attitude toward patient aggression amongst mental health nurses in the 'zero tolerance' era: associations with burnout and length of experience. Journal of Clinical Nursing. 11 (6), 819-825. 